\title{
La fiscalización de la actividad de los oficiales de la Generalitat de Cataluña en la época moderna. La Visita del General de Cataluña y su funcionamiento*
}

\section{The supervision of the members of the Generalitat de Cataluña in the Early Modern period. La Visita del General de Cataluña and its operation}

\author{
Ricard TORRA I PRAT \\ Investigador predoctoral FPU \\ Departament d'Història Moderna i Contemporània \\ Universitat Autònoma de Barcelona \\ ricard.torra.prat@gmail.com
}

Recibido: 15 de septiembre de 2014

Aceptado: 3 de diciembre de 2014

\begin{abstract}
RESUMEN
La Visita del General de Cataluña, fue la institución jurídica y política encargada de fiscalizar la actuación de los miembros de la administración del General o Generalitat de Cataluña, una vez estos finalizaban el ejercicio de sus cargos públicos. Este artículo, tiene como objetivo principal explicar las características y el funcionamiento de la Visita del General, ello especialmente a partir del análisis de las fuentes primarias de la que fue una de las principales instituciones públicas presentes en el Principado de Cataluña durante el reinado de la Casa de los Austrias.
\end{abstract}

PALABRAS CLAVE: Visita del General, Diputació del General, Historia institucional, siglo XVII.

\begin{abstract}
The Visita del General de Catalunya was a legal and politic institution whose aim was the public control of the members of el General or Generalitat de Catalunya at the ending of their public office government charge. The focus of this article is to explain the Visita del General's features and operations, through
\end{abstract}

\footnotetext{
* Este estudio se enmarca dentro del proyecto de tesis doctoral "La Visita del General de Catalunya: la institució i el seu encaix en el sistema institucional català altmodern (ss. XVI-XVIII)", dirigida por el Dr. Antoni Simon Tarrés y que cuenta con el respaldo del Grup de Recerca en Història Moderna Manuscrits (2014 SGR 232), del Departament d'Història Moderna i Contemporània de la Universitat Autonòma de Barcelona.
} 
the analysis of the primary documents and sources related to this institution, one of the principal public institutions of the Catalonia Principality during the Habsburg's dynasty reigns.

KEYWORDS: Visita del General, Diputació del General, Institucional History, $17^{\text {th }}$ Century.

\section{RÉSUMÉ}

La Visite du Général de la Catalogne fut l'institution juridique et politique chargée de contrôler la procèdure des membres de l'administration du Général ou Generalitat de la Catalogne, une fois leur exercice publique était terminé. La présente étude a comme but principal celui d'offrir des caractéristiques et fonctionnement de la Visite du Général, en particulier depuis l'analyse de la documentation primaire appartenante à une des principales institutions publiques présentes dans la Principat de la Catalogne durant le règne de la Maison d'Habsbourg.

MOTS CLÉ : Visite du Général, Diputation du Général, Histoire institutionnelle, XVII siècle.

SUMARIO: 1. Introducción. 2. Una sola legislación para todo el siglo: El Capítulo 1 del "Redreç" de 1599. 3. El Principio de la Visita. 4. La instrucción secreta: El período de la «ofensa». 5. La instrucción pública: la fase de la «defensa». 6. Los últimos tres meses: la fase de las sentencias. 7. Conclusiones.

\section{Introducción}

La "Visita del General de Catalunya", fue una institución jurídica y política encargada de fiscalizar la actuación de los miembros de la administración del General o Generalitat una vez estos finalizaban el ejercicio de sus cargos públicos. Aunque los orígenes más remotos del ente fiscalizador hay que buscarlos en el periodo bajomedieval, los primeros intentos de institucionalización de una Visita que se tendría que celebrar cada tres años datan de mediados del siglo XVI ${ }^{1}$.

Varios autores se han referido con más o menos profundidad a la Visita del Gene$\mathrm{ral}^{2}$, pero a día de hoy únicamente contamos con dos trabajos publicados que hayan

\footnotetext{
${ }^{1}$ Sobre los orígenes de las instituciones fiscalizadoras y su cristalización en la Visita del General, ver: Tomàs de Montagut, Les institucions fiscalitzadores de la Generalitat de Catalunya (des dels seus orígens fins a la reforma de 1413), Barcelona, 1996; Isabel Sánchez de Movellán, Les institucions fiscalitzadores de la Generalitat de Catalunya (Des de la reforma de 1413 fins al final del regnat de l'Emperador Carles I, el 1556), Barcelona, 2004. Especialmente las páginas. 146-152. Por lo que respecta a la aparición de las primeras visitas en Cortes y su proceso de institucionalización durante la segunda mitad del siglo XVI, Ricard Torra, "La Visita del General de Catalunya: una institució desconeguda, segles XVI-XVIII", Afers, fulls de recerca i pensament, 2014, pp. 149-171.

${ }^{2}$ Se han referido a la Visita del General más o menos extensamente: Àngel Casals, L'Emperador i els catalans: Catalunya a l'Imperi de Carles V: 1516-1543, Granollers, Editorial Granollers, 2000, especialmente las páginas 257-269; Jordi Buyreu, Institucions i conflictes a la Catalunya Moderna: Entre el greuge i la pragmàtica: 1542-1564, Barcelona, Rafael Dalmau, 2005, especialmente las páginas 103104; Miquel Pérez Latre, Diputació i Monarquia. El poder polític a Catalunya, 1563-1599. Tesi doctoral. 2001, especialmente pàginas 217-220. Desde la óptica de la historia del derecho, Víctor Ferro, El Dret Públic Català. Les Institucions a Catalunya fins al Decret de Nova Planta, Vic, Eumo Editorial, 1999. (Primera edición publicada en 1987). Sobre la Visita del General, ver las páginas 408 i ss.; Josep Capdeferro, "El vigor de les institucions de la Terra en la vigília dels Segadors", en Una relació dificil: Ca-
} 
hecho del centro de su estudio la propia institución, y de los dos, sólo uno intenta dar una visión de largo recorrido, puesto que el otro abarca parte de una sola Visita ${ }^{3}$.

Con el presente, nos proponemos explicar las características y el funcionamiento de una de las instituciones públicas vigentes en el Principado de Cataluña durante el reinado de los Habsburgo. Para ello, nos valdremos tanto de la riquísima documentación conservada en el Archivo de la Corona de Aragón, como de los diversos libros impresos de ordenanzas y funcionamiento referentes al funcionamiento de la Visita que los propios visitadores hicieron imprimir a lo largo del siglo XVII. Nuestro objetivo final, es aportar suficiente luz entorno la Visita del General, permitiéndonos situar de lleno el organismo dentro del campo de estudio de las instituciones fiscalizadoras de los oficiales públicos en los territorios de la Monarquía Hispánica de los Austrias.

Para llevar a cabo nuestro propósito, dividiremos el estudio en seis apartados: 1. En el primero de ellos, vamos a tratar sobre la legislación creada en las Cortes Catalanas de 1599 por la cual se implanta la Visita del General como institución. Además, también analizaremos como se desplegó esta legislación y como esto propició la aparición de las recopilaciones de ordenanzas sobre la Visita. 2. En el segundo de los apartados, abordaremos el análisis propiamente dicho de la institución. Concretamente, haremos incapié en los preparativos de la Visita, el espacio de tiempo comprendido entre la elección de los visitadores y el inicio de los nueve meses de la Visita. 3. En tercer lugar, examinaremos la fase de la instrucción secreta, conocida como fase de la "ofensa", en la que los visitadores se encargaban de recibir las demandas contra los oficiales cesantes de la administración de la Generalitat y fortificar las querellas que al final de dicha fase tenían que publicarse. 4. Seguidamente, haremos referencia a la instrucción pública de la Visita, en la fase conocida como "defensa", en la que la iniciativa pasaba a estar en manos de los acusados en las querellas publicadas al final de la instrucción secreta, los cuales contaban con tres meses para tratar de defenderse de las acusaciones vertidas sobre ellos. 5. En quinto lugar, analizaremos los últimos tres meses de la Visita, en la fase de las "sentencias", durante la cual los visitadores emitían su veredicto final acerca de las querellas. 6. Finalmente, dedicaremos las últimas líneas del trabajo a plantear las conclusiones pertinentes.

talunya i l'Espanya moderna (segles XVII-XIX), Barcelona, Base, 2007, pp. 47-84; del mismo autor: Joan Pere Fontanella (1575-1649), un advocat de luxe per la ciutat de Girona, Tesis doctoral inédita, 2010, particularmente las páginas 196-270.

${ }^{3}$ El primero de los artículos, obra de Pedro Llinás, intenta dar una perspectiva global sobre la Visita durante la segunda mitad del siglo XVII. Pedro Llinás, "La Visita del General: el procedimiento de control de los funcionarios dependientes de la Diputació del General de Catalunya (1653-1701)", Pedralbes, 10, 1990, pp. 177-192. Por su parte, el estudio de Eva Serra se centra en el análisis de la Visita foránea de un solo trienio. Eva Serra, "Territori i inspecció fiscal: la Visita del General del 1600", en Les xarxes urbanes a la Catalunya dels segles XVI i XVII, Barcelona, Rafael Dalmau, 2012, pp. 165-284. 


\section{Una sola legislación para todo el siglo: El Capítulo 1 del "Redreç" de 1599}

Construiremos la primera parte de nuestro análisis a partir de la creación de la principal legislación para la Visita durante todo el siglo XVII, esto es, el Capítulo del Redreç $1 / 1599^{4}$. Este venía a culminar el proceso iniciado anteriormente en las Cortes de 1542, momento en el cual, por primera vez, se habría intentado la creación de una fiscalización de la actividad de los oficiales de la Diputación una vez que estos terminaban su ejercicio político 5 .

En el testimoniaje de los coetáneos, se puede apreciar un cierto grado de satisfacción al valorar el contenido de la legislación producida por las Cortes de 1599, sobre todo al compararlo con la producida en las de 1585, que desembocaron en el período

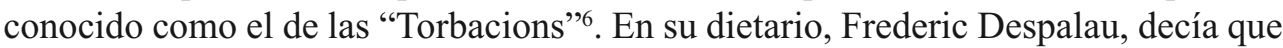
"An-se ordenades constitucions de molta importància, à consedit Sa Magestat tot lo que se li à demanat: la visita dels de la Audiència y la de la Diputació y lo nou red[r]ès de la Deputació y an abolit lo vell, so és, lo de [15]85, lo qual causà molts danys a la terra. Consedi's tot de tal manera que no y avie més que desiyar"' Como vemos, entre los muchos elementos que el noble barcelonés destacaba de las últimas Cortes Catalanas del siglo XVI, se hacía referencia explícita al nuevo ordenamiento referente a la Visita del General. Para bién o para mal, la legislación aprobada, tendría vigencia todo el siglo XVII, puesto que no finalizarían otras Cortes hasta principios del siglo XVIII y ya con el primer monarca de la casa de Borbón en el trono ${ }^{8}$.

El capítulo del Redreç 1/1599, titulado "Visita del General", supuso romper con todos los ordenamientos que las Cortes habían hecho previamente acerca de la institución, especialmente con el de 1542, puesto que, a diferencia de este, ahora se les quitaba la potestad de visitar a los nuevos miembros de la Diputación entrantes, y se daba esta a un nuevo consistorio creado a tal efecto. También se rompía con el sistema de visitas ideado en las Cortes de 1585, el cual preveía la creación de las polémicas "divuitenes" - reuniones de dieciocho miembros de los tres estamentos, concretamente seis por estamento- que en gran medida habían contribuído al enfrentamiento entre la Diputación y Felipe II.

\footnotetext{
${ }^{4}$ Según Oriol Oleart, los “Capítols del Redreç" fueron aquellos capítulos de Corte referentes a las disposiciones que las Cortes elaboraron para regular todos los aspectos tocantes al funcionamiento de la Diputación del General y sus tributos. Oriol Oleart, "La creació del dret: els anomenats capítols del redreç del General de Catalunya, Pedralbes: Revista d'història moderna, 13/1, 1993, pp. 245-258.

${ }^{5}$ Concretamente a partir del Capítulo del Redreç 15/1542. ACA, Generalitat, Serie G, 150/4.

${ }^{6}$ Sobre el período de las turbaciones políticas posteriores a las Cortes de 1585 , ver básicamente la tesis ya citada de Miquel Pérez Latre. Una buena síntesis,del mismo autor en "La Diputació del General i les torbacions polítiques de 1587-1593", en Història de la Generalitat de Catalunya. Dels orígens medievals a l'actualitat, 650 anys, Barcelona, Institut d'Estudis Catalans, 2011, páginas 163-178.

${ }^{7}$ Antoni Simon, Cavallers i ciutadans a la Catalunya del cinc-cents, Barcelona, Curial, 1991, pp. 172-173.

${ }^{8}$ Acerca de las Cortes catalanas de 1701-1702, vid.: Josep Maria Torras i Ribé: La Guerra de Successió i els setges de Barcelona (1697-1714), Barcelona, Rafael Dalmau, 1999, especialmente pp. 56 i ss.
} 
A diferencia de estos dos ordenamientos, a partir del Capítulo 1/1599 se creaba ex profeso un sistema parecido al de la Diputación, regido por el sistema de insaculación, tutelado por los estamentos (Braços) y por los diputados y oidores de cuentas de la Generalitat. Cada nuevo trienio, las personas que se consideraban aptas para concurrir en la nueva bolsa de visitadores, eran los que previamente habían sido inscritos como válidos para participar en las bolsas de Diputado u Oidor de Cuentas del General, aunque quedaban totalmente descartados aquellos que tuvieran que ser visitados por el nuevo tribunal. De entre todas las personas insaculadas, se hacía extracción de nueve, tres de cada estamento o Braç, los cuales a partir de aquél momento devenían visitadores del trienio anterior?.

La legislación también determinaba que los nuevos visitadores tenían como obligación "visitar y conèxer de tots los excessos y culpes que-s trobarà haver comesos los diputats, oydors, los assessors, advocat fiscal y demés officials del General, tant residint dins la present ciutat de Barcelona com fora d·ella" ${ }^{10}$. Se dejaba claro así la labor fiscalizadora de los miembros de la Visita, así como también la obligación que estos tenían de revisar las actuaciones de los oficiales de la Generalitat en todo el territorio.

Siguiendo el Capítulo del Redreç 1/1599, las Cortes también dispusieron que de entre los nueve visitadores extraídos, se tenía que elegir a tres, uno de cada estamento, los cuales se encargaban de la instrucción de los procesos. Dicha elección se hacía, normalmente, el 16 de agosto de cada nuevo trienio, cuando los visitadores escenificaban la toma de posesión del cargo en la ceremonia del juramento. En el caso que alguno de los visitadores extraídos renunciara o no se encontrara en condiciones de ejercer el cargo, la legislación determinaba que se procediera a hacer una nueva extracción para suplir la vacante ${ }^{11}$. También existía la posibilidad que los procesados por la Visita, pudieran recusar a uno o varios miembros del tribunal, aunque siempre que las incompatibilidades fueran las "legítimes suspites [...] que de dret seran tingudes per tals per a remourer un jutge y no altres".

La legislación trasladaba a los visitadores la potestad de elegir los oficiales mayores y menores, así como los oficios de la Visita. Estos "funcionarios" de la Visita, eran elegidos "a més veus" -mayoría simple- por el consistorio de la Visita durante los primeros días de funcionamiento de este. Según el Capítulo, tenían que elegirse dos asesores, uno de los cuales tenía que ser abogado fiscal "de trenta anys de edat y

\footnotetext{
9 "Determina la present Cort que lo primer dia Jurídich aprés del jurament dels nous Diputats, cada trienni se hajan de convocar les persones dels tres staments que les hores se trobaran presents en la Ciutat de Barcelona ab veu de pública crida en la casa de la Diputació, y en presència de ellas se fassa extractió de nou persones, tres de cada stament, de la manera y forma que 's sol fer la extractió de Diputats y Oydors, juntant los redolins dels Diputats ab los dels Oydors de son stament". Archivo de la Corona de Aragón (ACA), Generalidad, Serie G, 152/3.

${ }^{10}$ Ibid.

11 "Y en cas algú, o alguns dels visitadors no acudiessen dit dia setze de Agost, se faça encontinent en lloch de aquell o, aquells, semblant extractió ab termini de quinse dias per acudir a dit exercici, y que semblant extractió se faça ab lo mateix termini de quinze dias fins que lo número estiga complit". Idem.
} 
sis anys cumplits de plàtiga [sic] del present Principat", un notario - para ejercer como escribano mayor-, un procurador fiscal y "los demés officials que aparexeran necessaris per a millor fer y proseguir dita Visita" -es decir, los visitadores tenían total libertad para crear todos aquellos oficios que fueran necesarios para el funcionamiento de la institución-. También se especificaban muy claramente los salarios que debían percibir los oficiales de la Visita, aunque es cierto que se dejaba un margen amplio a los visitadores para mejorar las retribuciones, sobretodo en los cargos creados por los propios visitadores ${ }^{12}$.

Las Cortes también determinaron la duración de la Visita. Según el redactado de la ley, la Visita tenía que durar nueve meses divididos en tres fases: los primeros tres meses se tenían que dedicar a la instrucción de los procesos, los tres siguientes a la defensa de los acusados y, los tres últimos, a la redacción y publicación de las sentencias de la Visita. Aunque como bien ha dicho Eva Serra, la Visita no podía sobrepasar el término de los nueve meses prefijado por las Cortes, cierto es que los visitadores en algunos casos podían alargar las gestiones hechas una vez publicadas las sentencias ${ }^{13}$. Finalmente, según el redactado del capítulo, se dejaba muy claro que sobre las declaraciones, procedimientos y sentencias realizadas por los visitadores, no se pudiera "suplicar, recórrer ni apel·lar"'l4.

En definitiva, el redactado de la ley, dejaba claras las líneas maestras que tenían que regir la nueva institución, pero el desarrollo de la misma tendría que correr, por fuerza, a cargo de los propios visitadores y de la mano de otra de las fuentes típicas del derecho durante el antiguo régimen: la costumbre. Es en este contexto que debemos entender la aparición de las cuatro recopilaciones hechas a lo largo del siglo XVII por los propios visitadores, referentes a la Visita y su funcionamiento. Cronológicamente, dichas compilaciones fueron las siguientes: El Sumario de la Visita de $1626^{15}$, El Directorio de la Visita de $1636^{16}$, El Directorio de la Visita de $1672^{17}$ y el Directorio de la Visita de $1698^{18}$.

\footnotetext{
${ }^{12}$ Según el Capítulo 1/1599 los visitadores instructores de procesos debían percibir 300 libras. El resto de los visitadores, los no instructores, 200 libras. Los asesores, 150 libras, aunque ampliables a un máximo de 400 dependiendo de la carga de trabajo. La retribución del resto de oficiales quedaba al arbitrio de los visitadores.

${ }^{13}$ Eva Serra, "Territori i inspecció fiscal...", p. 177

${ }^{14}$ La imposibilidad de vertir causa de apelación sobre las sentencias de la Visita se respetó hasta el año 1660, cuando la monarquía decidió dar cobertura jurídica -mediante Real Decreto- a las apelaciones vertidas contra las sentencias de la Visita en la Real Audiencia de Cataluña en los casos de "notoria injusticia". ACA, Generalidad, Serie G, 6/10, f. 148. Cfr. Pedro Llinás, La Visita del General: el procedimiento..., p. 182.

${ }^{15}$ Summari, compendios y substancial dels procehiments, sentèncias y provisions de la Visita del General de Cathalunya, feta contra los Deputats, Oydors y Officials del dit General, que son estats en lo trienni del any 1623, fins en lo del any 1626, per a major effectuació y observança de aquellas, a utilitat y benefici de dit General, Barcelona, Geroni Margarit, 1628. Biblioteca Universitària de Barcelona (BUB), Fons Antic, 07 B-62/4/20.

${ }^{16}$ Directori de la Visita del General de Catalunya, y Breu sumari de sentèncias de las Visitas fetas des de lo any 1599 fins la última feta en lo any 1635, que importan dispositió en lo esdevenidor en benefici del General, Barcelona, Gabriel Nogués, 1636. BUB, Fons Antic, 07 B-59/6/28.
} 
La principal característica de estos cuatro libros impresos, es que desarrollan en gran medida las líneas maestras prefijadas por el Capítulo 1 del Redreç de 1599, en base a la experiencia de las diversas visitas hechas a lo largo de los años. Además, permiten al historiador ver la evolución de la institución a lo largo del siglo porque, aunque hay muchas similitudes entre ellos - especialmente en el caso de los tres directorios, el de 1636, el de 1672 y el de 1698-, cada nueva edición presenta alguna novedad respecto al redactado anterior. Es por este motivo, que para hacer frente al principal objetivo de este artículo -que como dijimos es mostrar el funcionamiento de la institución durante el siglo XVII- vamos a seguir las pautas marcadas en estas recopilaciones, ampliadas con ejemplos que podemos encontrar en los dietarios de la institución y otras fuentes coetáneas.

Antes de pasar al quid de la cuestión, queremos plantear las tres razones que, a nuestro entender, motivaron la aparición de las recopilaciones del siglo XVII anteriormente citadas: 1 . En primer lugar, y como hemos insinuado anteriormente, la necesidad de poner por escrito el desarrollo de la legislación salida de las Cortes de 1599 referente a la Visita. Creemos que tanto el Sumario de la Visita de 1626 como los directorios de 1636, 1672 y 1698 rellenan los vacíos y las lagunas jurídicas del capítulo 1/1599 mediante la costumbre. 2. En segundo lugar, los compendios ayudarían a solucionar la falta de continuidad entre consistorios de visitadores, derivada del límite temporal de nueve meses por trienio. Con la impresión de las normas a seguir por los consistorios, la actividad de los mismos se volvería mucho más coherente, existiendo cada vez menos diferencias entre la acción de las distintas Visitas. 3. Finalmente, creemos que la impresión y difusión de las normas internas de la Visita tendría también una clara motivación de dar a conocer la institución a los contemporáneos de la época, es decir, que con ello se quería dotar al consistorio de un marcado carácter institucional ${ }^{19}$.

Pasemos pues a ver como funcionaba la institución desde la elección de los cargos de la Visita, hasta la publicación y ejecución de las sentencias de la misma hecha por los visitadores.

\footnotetext{
${ }^{17}$ Directori de la Visita del General del Principat de Catalunya y Comptats de Rosselló y Cerdanya: y capitols resultants acerca dels càrrechs, y obligations dels senyors diputats, y oydors y oficials de la Casa de la Deputació y General de Catalunya y altres, Barcelona, Antoni Lacavalleria, 1672. BUB, Fons Antic, 07 B-59/6/28.

${ }^{18}$ Directori de la Visita del General del Principat de Catalunya y Comptats de Rosselló y Cerdanya: y capitols resultants acerca dels càrrechs, y obligations dels senyors diputats, y oydors y oficials de la Casa de la Deputació y General de Catalunya y altres. Van anyadits en esta última reimpressió las ciutats, vilas y llochs del present Principat y Comptats de Rosselló y Cerdanya distribuïts per sas Veguerias, Barcelona, Rafel Figueró, 1698. BUB, Fons Antic, 07 B-61/5/12.

${ }^{19}$ Por ejemplo, sabemos que del Directorio de 1636 se hicieron imprimir doscientos tomos, cantidad un tanto exagerada si no asumimos que dichas obras gozaban de cierta circulación entre la clase dirigente del momento, más allá del uso interno de la institución. ACA, Generalidad, Serie G, 6/4, f. 195.
} 


\section{El Principio de la Visita}

El inicio de las gestiones relacionadas con la Visita se daba con motivo de la convocatoria para celebración de la ceremonia de extracción de los visitadores. Esta última, normalmente se celebraba el día 2 de Agosto, coincidiendo con cada nuevo comienzo de trienio en la Diputación catalana. Como hemos visto en el Capítulo $1 / 1599$, eran los propios diputados los encargados de llamar a los miembros de los estamentos para que participassen en dicha ceremonia ${ }^{20}$. En esta, se extraían mediante el ya citado sistema de la insaculación tres visitadores por cada estamento, eso es, tres por el estamento eclesiástico, tres por el militar, y tres por el real. Finalizada la ceremonia, los diputados encargaban a los mensajeros de la Diputación catalana que fueran a comunicar la noticia a los elegidos, los cuales tenían que presentarse en Barcelona el dia 16 de agosto para jurar el cargo.

El juramento, como la extracción, se hacía mediante otra ceremonia celebrada en la Casa de la Diputación, en la que los visitadores también recibían sentencia de excomunión por parte del Vicario General, delegado del Obispo de Barcelona. Hecho esto, los visitadores que se encontraban presentes, hacían una nueva extracción en la que solo concurrían los que hubieran jurado, y en la cual se sacaban los tres visitadores encargados de instruir de procesos ${ }^{21}$.

Seguidamente, los consistoriales se reunían en su consistorio, normalmente situado en la Casa de la Diputación, en las salas colindantes a la Capilla de San Jorge, aunque a partir de la lectura de los dietarios de la Visita sabemos que no siempre fue así y que, por lo menos hasta 1635, hubo una cierta tendencia en situar la sede física del tribunal en domicilios particulares situados en el centro de la ciudad condal. Las motivaciones para actuar así las dejaban claras los miembros de la Visita iniciada en agosto de 1608; según ellos, la Casa de la Diputación no tendría las habitaciones necesarias para albergar el consistorio de la Visita y se deberían de vaciar algunas de las que se utilizarían tanto para oficiales subalternos como de archivo a la Diputación, con los previsibles contratiempos que la mudanza de los documentos podría suponer para dicha institución. Debido a estos contratiempos, los visitadores creían que era mucho mejor buscar una casa situada en el centro de Barcelona lo suficientemente grande como para albergar el consistorio de la Visita ${ }^{22}$.

\footnotetext{
${ }^{20}$ Para una descripción detallada de la misma, vid. Ricard Torra, "La Visita del General...", pp. 161165. Un buen ejemplo lo podríamos encontrar también en Dietaris de la Generalitat de Catalunya (DGC), vol. IV, p. 425.

${ }^{21}$ Directori de la Visita del General..., 1636, pp. 5-6. Para esta segunda ceremonia, vid. Ricard Torra, "La Visita del General...", pp. 164-165; DGC, vol. VIII, p. 828; también hay información en ACA, Generalidad, Serie VG, 50, volumen sin foliar, entrada titulada "Dissabte, a 16 de Agost, 1614" y en el Llibre del Cerimonial, ACA, Generalidad, Serie G, 71/1, f. 59.

${ }^{22}$ Muy especialmente ACA, Generalidad, Serie VG, 34, s/f(19-VIII-1608). Otros ejemplos de elección de sedes diferentes a la Casa de la Diputación: ACA, Generalidad, Serie G, 6/1/2, f. 9v; ACA, Generalidad, Serie G, 6/3, s/f (21-VIII-1629).
} 
Elegido el lugar de residencia, los visitadores se reunían en este y hacían elección de los oficiales de la Visita. En los directorios y en el capítulo 1 del Redreç de 1599, estos están limitados, como hemos visto, a dos asesores, uno de los cuales tenía que ejercer como abogado fiscal, un escrivano mayor y un procurador fiscal, aunque cabe la posiblidad de ampliar los oficiales al número que los visitadores consideraran oportuno. Las cifras de oficiales, son dispares dependiendo del trienio que revisemos, aunque hay dos tendencias más o menos claras: la primera, que hasta 1652 los visitadores escogieron un número sensiblemente superior de oficiales al que escogieron a partir de esta fecha, básicamente por motivos económicos. La segunda, que durante la mayor parte de las visitas hechas entre 1600 y 1640 se elegían los llamados "delegats forans", encargados de realizar la visita por todas las circunscripciones fiscales del Principado $\mathrm{y}$, debido al elevado coste de sistema, se decide prescindir de él de forma definitiva coincidiendo con el estallido de la Guerra dels Segadors. Así pues, teniendo en cuenta estas premisas, podemos decir que la planta de la institución, en cuanto a oficiales se refiere, presentaba normalmente la siguiente forma: los nueve visitadores, un asesor, un abogado fiscal, un escribano mayor, un procurador fiscal, un ayudante del asesor, un ayudante del abogado fiscal, dos (o incluso tres) ayudantes del escribano mayor, seis calculadores, seis "portalers", dos "porters", dos "escombradors" o barredores y un "encenedor del foch" "23. Hecha la nominación de los oficiales, estos solían jurar el cargo en los días siguientes ante los visitadores reunidos consistorialmente.

Otro de los elementos de los que los visitadores se preocupaban durante los primeros días de la Visita, era la provisión de todos los elementos necesarios para el desarrollo de esta. En este sentido, en algunos de los dietarios encontramos memoriales con los objetos que se tienen que comprar, como por ejemplo libros de la legislación vigente (Constituciones Catalanas, Capítulos de Corte, ...), obras jurídicas como las Decisiones de Lluís de Peguera, materiales para la escribanía — tinta, plumas, papel, tinteros, etc. - velas para la iluminación del consistorio o carbón y leña para calentar las estancias en la época inverna ${ }^{24}$.

El último de los preparativos, era la deliberación a instancia del procurador fiscal de la Visita por la cual se acordaba publicar las "Crides de la Visita" y la posterior publicación de las mismas. En este texto, que era enviado a todos los rincones del Principado, los visitadores hacían saber que, en base al Capítulo 1/1599, a partir del inicio de la fase de la ofensa - normalmente el dia 15 de septiembre- todo aquel que quisiera y tuviera los motivos necesarios, podía denunciar cualesquiera actuaciones contra derecho hechas por los oficiales de la Diputación del General, tanto los residentes en Barcelona como los residentes fuera de ella ${ }^{25}$.

\footnotetext{
${ }^{23}$ ACA, Generalidad, Serie G, 6/9, s/f. Normalmente, al principio de cada dietario de la Visita, se encuentra una relación de todas las personas que obtuvieron un oficio en dicho trienio.

${ }^{24}$ ACA, Generalidad, Serie G, 6/1/1, f. 5v-6v.

${ }^{25}$ Directori de la Visita..., 1636, p. 9. El texto completo de la "Crida" por ejemplo en, ACA, Generalidad, Serie G, 6/19, f. 14r-16r. Concretamente, los delictos que podían ser causa de denúncia a los visitadores
} 


\section{La instrucción secreta: El período de la «ofensa»}

Como hemos dicho, el período de la ofensa normalmente se iniciaba cada 15 de septiembre y se alargaba durante tres meses, hasta el dia 15 de diciembre ${ }^{26}$. Durante esta fase -la que presenta una mayor producción documental- el consistorio de los visitadores se encargaba de hacer las gestiones necesarias para fortificar las querellas contra los oficiales del General del trienio anterior que, bien el procurador fiscal, bien los particulares u otras instituciones del Principado, les presentaran ${ }^{27}$.

Para que el consistorio pudiera recibir las denuncias de particulares y/o instituciones externas de forma correcta, se diseñó un sistema de cajas que se situaban, por lo que respecta a la sede central, en tres de los principales accesos a la Casa de la Diputación ${ }^{28}$; en cambio, en el caso de las denuncias hechas contra los oficiales foráneos, es decir, de fuera de Barcelona, los visitadores mandaban a los encargados de la administración de la Diputación repartidos por el territorio -los diputados locales ${ }^{29}$ que pusieran una caja en cada sede de la administración local para que se depositaran allí las denuncias. Para que los diputados locales tuvieran noticia de su cometido para con la Visita, los Visitadores les escribían cartas en las cuales se les informaba de las gestiones a realizar. Normalmente, además de hacer colocar una caja para las denuncias, los diputados locales tenían que publicar las cridas de la Visita en todas las localidades de su territorio ${ }^{30}$.

eran todos aquellos que "qualsevols officials y ministres de dit General no hajan servat lo que per constitucions, ordinacions, capítols y actes de Cort, usos, estils y pràctica de la Generalitat eran tinguts y obligats fer y servar. E si dits deputats, ohidors, assessors, advocats fiscals, deputats locals, cullidors y guardas y altres officials del General o algú d·ells per si, o per interposada persona directa, o indirecta ha rebut pecúnia alguna o altre qualsevol cosa per provisió de offici o officis, insiculacions, y altres qualsevols cosas tocants al general, o hajan fet frau tant en la exactió dels drets de dit General com altrament en la distribució de la hisenda y patrimoni de aquella per qualsevol via y manera, donat o permès offert inciculacions o officis que tot ho denuncien ab tota veritat als dits illustres y molt reverents senyors visitadors".

${ }^{26}$ En materia de fechas, hay algunas excepciones. Por ejemplo, en la Visita hecha en 1654 y debido a las consecuencias del fin de la Guerra dels Segadors -los diputados que tenían que terminar su mandato en 1653, lo alargaron hasta 1654 por orden de Felipe IV, mientras Madrid decidía las modificaciones que introducía en la Generalidad y el Consell de Cent-, la Visita se inició a finales del mes de abril y la fase de ofensa el dia 25 de mayo. ACA, Generalidad, Serie G, 6/8, f. 10.

${ }^{27}$ En este sentido, el asesor y el abogado fiscal tenían que encargarse solamente de fortificar las querellas que tuvieran fundamentación jurídica, evitando las calumniosas. Directori de la Visita..., 1636, p. 11.

${ }^{28}$ Directori de la Visita..., 1636, p. 10.

${ }^{29}$ Eva Serra trató hace ya algunos años el papel de las Diputaciones Locales como órganos delegados de la Diputació del General a nivel local para la gestión del territorio en el Principado de Cataluña. Las principales tareas de los diputados locales, consistían en perseguir los delitos y el fraude fiscal así como juzgar los contenciosos locales derivados de la recaptación fiscal de los derechos de la Generalitat. Eva Serra, "Diputats locals i participació social en les bolles de la Diputació del General (1570-1638). Una mostra i una reflexió", Pedralbes. Revista d'Història Moderna, 13/1,1993, pp. 259-274. Muy especialmente la p. 260.

${ }^{30}$ Un ejemplo de carta enviada por los visitadores a un diputado local referente a las gestiones a realizar en favor de la Visita a ACA, Generalidad, Serie G, 6/4, f. 14v-15r. 
Dentro de la fase de la ofensa, la instrucción se dividió a lo largo del siglo entre las querellas presentadas directamente en la sede central de Barcelona, y las querellas foráneas, es decir, todas aquellas que no se presentaban en Barcelona y que, por lo general, eran presentadas en las sedes de las diputaciones locales, como ya hemos dicho. Para organizar la recopilación foránea, la Visita utilizó básicamente dos sistemas:

1. La visita foránea con oficiales creados ex profeso para la tarea. Hasta 1640, la mayoría de las Visitas que se hicieron contaron con el sistema de la Visita foránea para la realización de la fase de la ofensa en todo el territorio del Principado. Dicho sistema, analizado recientemente por Eva Serra ${ }^{31}$, consistía en la nominación de dieciséis oficiales foráneos distribuídos entre las cuatro "veredes" o circunscripciones fiscales en las cuales estaba dividida Cataluña en el período moderno. Cada vereda contaba con un asesor foráneo, un notario foráneo, un procurador fiscal foráneo y un "porter" foráneo, los cuales se encargaban de recorrer el territorio, visitando todos aquellos sitios en los cuales hubiera oficiales del General. Las atribuciones de estos delegados foráneos eran muy parecidas a las de los visitadores de Barcelona, aunque con algunas limitaciones ${ }^{32}$. Al partir, normalmente se les entregaban instrucciones que se íban modificando a medida que avanzaban en su inspección. Aunque su tarea fundamental era la de recoger por todo el territorio las querellas dipositadas en las cajas de las diputaciones locales, también se les encargaban otros menesteres, tales como: la inspección de las herramientas de los oficiales encargados de marcar las mercancías que pagaban tributo a la Generalitat, determinar si los oficiales locales de la Diputación lo eran también reales o de la inquisición (condiciones incompatibles), si estos ejercían el cargo directamente o mediante sustituto, si hacían residencia en el lugar de ejercicio del cargo, si utilizaban herramientas falsas para defraudar tributos, etc ${ }^{33}$.

2. La visita foránea utilizando la red de diputaciones locales. Este sistema fue el más utilizado a lo largo del siglo XVII. Ideado por el consistorio liderado por Pau Claris en 1626, y aplicado también por el consistorio de 1635, fue una constante a partir del trienio de 1641. Mediante deliberación del consistorio de la Visita a 31 de

\footnotetext{
${ }^{31}$ Eva Serra, “Territori i inspecció fiscal...”, pp. 165-284. La creación del sistema de oficiales foráneos, propició la aparición de Dietarios de la Visita Forana, algunos de los cuales se conservan en el Archivo de la Corona de Aragón, dentro de la Serie VG.

${ }^{32}$ Aunque sus poderes eran amplios y podían, por ejemplo, imponer suspensiones de cargos tal y como lo hacían los visitadores de Barcelona, los delegados foráneos siempre estaban bajo las órdenes del consistorio central y su actuación tenía que regirse por la ley. En caso de no proceder de este modo, se les podía suspender, tal y como sucedió en la Visita realizada en 1638. ACA, Generalidad, Serie G, 6/5, f. 110 r.

${ }^{33}$ Eva Serra, "Territori i inspecció fiscal...", pp. 196-197. El trabajo de Eva Serra hace referencia a la Visita Forana de 1600. En las actas de la Visita de 1614 se recogen otras instrucciones hechas a los delegados foráneos mucho más completas que las de 1600, lo que nos indica que a cada nueva Visita, se ampliaban las tareas a realizar, probablemente fruto de la experiencia adquirida. ACA, Generalidad, Serie VG, 50, documento datado a 11 de Octubre de 1614.
} 
Agosto de 1626, se diseñaban las nuevas visitas foráneas, la principal característica de las cuales era que los encargados de la inspección eran, a partir de este momento, los diputados locales que se encontraran en el ejercicio del cargo. A estos, se les encargaba el control de la caja de las denuncias en su demarcación, la recepción de las denuncias secretas, la publicación de las cridas, el control y revisión de las herramientas de los oficiales encargados de marcar las mercancías tributables, entre otros ${ }^{34}$. El diputado local, pasaba a ser la figura central de la inspección fuera de Barcelona, motivo por el cual se le entregaban instrucciones y poderes para indagar en las denuncias y posteriormente fortificarlas. Ahora bien, estas siempre pasaban por el "filtro" de Barcelona, puesto que el diputado local no podía actuar de oficio, sino que debía enviar primero las querellas a los visitadores para que los asesores de la Visita las analizaran ${ }^{35}$. Se trataba, en definitiva, de repartir las tareas de las visitas foráneas entre las diputaciones locales y la sede central, motivo por el cual se crearían los oficios de ayudante del asesor y ayudante del abogado fiscal, hecho que posteriormente recogió el Directorio de la Visita de $1636^{36}$.

La actividad en el consistorio de Barcelona, concentraba tanto la recepción de todas las querellas del Principado, como la averiguación de los delitos cometidos por los investigados en el territorio immediatamente dependiente de la ciudad condal. Gracias a la documentación conservada en los dietarios de la institución, podemos llegar a reconstruir el dia a dia de los consistoriales en el ejercicio de sus cargos. Sabemos, por ejemplo, que normalmente se hacía residencia en la sede de la Visita los días laborables, unas cuatro horas diarias: normalmente de nueve a once por la mañana y de tres a cinco por la tarde, aunque este horario podía variar dependiendo de la época del año ${ }^{37}$.

Los visitadores algunas veces empezaban la jornada revisando las cajas de las denuncias. En esta revisión, participaban normalmente todos los oficiales presentes en aquel momento dentro del consistorio. Una vez reconocidas todas las cajas, si se habían encontrado en ellas denuncias, estas se leían delante de todo el consistorio y, posteriormente, eran entregadas al abogado fiscal para que las adequase a los cánones de la ley ${ }^{38}$.

\footnotetext{
${ }^{34}$ ACA, Generalidad, Serie G, 6/1/2, f. 16v-17r.

${ }^{35}$ ACA, Generalidad, Serie G, 6/4, f. 78r-79r. Directori de la Visita..., 1636, p. 11.

${ }^{36}$ El Directorio era muy explícito respecto a las motivaciones para crear el nuevo sistema: "Per quant és de molt gran benefici al General escusar [eliminar] les quatre veredes, que·s fan en la visita per fora la ciutat de Barcelona, ab les quals se gastan cerca de sinch milia lliures, y ha mostrat la experiència ser de molt poch profit, com resulta de molts processos de visitas: per tant, seran necessaris un ajudant de assessor, y un altre de advocat fiscal, als quals serà bé encomanar tot lo que tocarà a les collectes foranes". Directori de la Visita..., 1636, p. 8.

${ }^{37}$ Por ejemplo, en el dietario del año 1662, los visitadores disponen que hasta el día de San Miguel el horario fuese de nueve a once por la mañana y de tres a cinco por la tarde. A partir de esta fecha, el horario pasaría a ser de nueve a once por la mañana y de dos a cuatro por la tarde. ACA, Generalidad, Serie G, 6/11, f. 4r y 5v-6r.

${ }^{38}$ ACA, Generalidad, Serie G, 6/8, f.170.
} 
Después de la revisión de las cajas, los visitadores proseguían con sus quehaceres cuotidianos que podían ser de diversa índole. A continuación, haremos referencia a los más recurrentes.

1. Revisar la correspondencia. Los visitadores tuvieron una elevada correspondencia, tanto de índole interna, como de índole externa. Internamente, los visitadores utilizaban la correspondencia para comunicarse bien con los delegados foráneos, bién con los diputados locales, aunque también podían enviar cartas a particulares para que les hicieran determinados trabajos o a los visitadores no instructores de procesos para comunicarles novedades acerca del consistorio u requerirles su presencia ${ }^{39}$. De forma externa, por ejemplo, los visitadores tuvieron una amplia correspondencia con la administración real durante la segunda mitad del siglo XVII, derivada de las reformas que la monarquía introdujo en la institución ${ }^{40}$. Relacionada con esta temática, encontramos la correspondencia entre los visitadores y sus agentes en la corte de Madrid, los cuales se encargaban promocionar las peticiones de la Visita en el Consejo Supremo de Aragón ${ }^{41}$.

2. La gestión económica de la institución. Aunque dicha tarea se daba a lo largo de les nueve meses de la Visita, durante los primeros esta se daba con una intensidad algo mayor. El dinero del que disponían los visitadores normalmente era entregado por el oficio del Regent els Comptes del General, el cual estaba a cargo de proveer de dinero tanto el consistorio de la Diputación como el consistorio de la Visita. Una vez conseguido el dinero, los visitadores lo utilizaban para hacer frente tanto a los salarios de los oficiales como a la compra de los materiales necesarios para el consistorio ${ }^{42}$.

3. La resolución de conflictos externos con otras instituciones públicas. A lo largo de todo el siglo, la Visita tuvo enfrentamientos con la mayoría de las otras instituciones públicas presentes en el Principado -Diputación, Consell de Cent, Braç Militar, Real Audiencia y Virrey-, normalmente por motivos jurisdiccionales. Aunque cabe

\footnotetext{
${ }^{39}$ Para ver un ejemplo de carta enviada a un delegado foráneo, ACA, Generalidad, Serie G, 6/3, f. 23v24r. Una carta enviada por un diputado local a los visiatdores en ACA, Generalidad, Serie G, 6/8, f. $48 \mathrm{v}-49 \mathrm{r}$. Un ejemplo de carta enviada a un visitador no instructor de procesos en ACA, Generalidad, Serie G, 6/1/1, f. 46.

${ }^{40}$ Sobre este punto en concreto vid. Ricard Torra, "Mites o Realitats? Sobre el paper de les Corts catalanes altmodernes com a generadores de dret. El cas de la Visita del General", Estudis: Revista de Historia Moderna, 40, 2014, pp. 115-132. Hacemos referencia explícita a las pp. 124-128.

${ }^{41}$ Sobre la correspondencia mantenida entre los visitadores y la monarquía, hay que decir que el canal vehiculador normalmente fue el virrey. Los visitadores le enviaban los memoriales y este los remitía a Madrid, para que fuesen estudiados en el Consejo Supremo de Aragón. Hay muchísimos ejemplos de dicha correspondencia en los dietarios de 1662, 1665, 1668, 1671 y 1674 . En cuanto a la correspondencia con el agente de la Visita en la Corte, por ejemplo, ACA, Generalidad, Serie G, 6/16, f. 58 i ss. En aquellos años, Magí Vilana Perlas fue el agente de la institución en Madrid.

${ }^{42}$ Para ver un registro de la paga a los oficiales: ACA, Generalidad, Serie G, 6/7/2, f. 75r-76r. Respecto a la compra de materiales para el consistorio, por ejemplo, el dia 22 de Noviembre de 1629 se disponía que se comprase madera para poder encender el fuego del consistorio y combatir así el frío. ACA, Generalidad, Serie G, 6/3, f. 41r.
} 
decir que la confrontación no fue la norma, sino que normalmente los visitadores intentaban colaborar con las otras instituciones e incluso pedirles consejo. En este sentido, fueron recurrentes las reuniones entre los asesores de la Visita y los doctores de la Real Audiencia para tratar todo tipo de dudas de carácter jurídico que podían surgir en el momento de instruir los procesos y/o aceptar las denuncias ${ }^{43}$.

4. La recepción de los testigos y fonamentación de las querellas. Muy importante durante periodo de la ofensa era la recepción de los testigos que permitían fortificar las querellas. El Directorio de 1636 es tajante en esta cuestión, puesto que manifiesta que las querellas tienen que contar con testimoniajes fidedignos además de la acusación del fisco para que sean válidas. En este sentido, los visitadores podían bién recibir los testimonios en Barcelona, bién encargar el interrogatorio a una tercera persona de su confianza en caso que el testigo alegara imposibilidad de desplazarse a la ciudad condal ${ }^{44}$. En el caso de aquellos que se resistían a prestar declaración, podían ser requeridos mediante citación judicial ${ }^{45}$-llamada "lletra citatòria"-.

Todas las gestiones hechas por el consistorio durante los tres primeros meses de la Visita tenían un claro objetivo: conseguir fundamentar el mayor número de querellas posibles para posteriormente decidir si estas debían ser o no publicadas durante los últimos días de la fase de la ofensa. Esta fase antes de la publicación, se llamaba "habilitación de las querellas" y, según dispone el Directorio de 1636, en ella tenían que participar todos los nueve visitadores, tanto los instructores como los no instructores, aunque hay que decir que la tendencia fue que los no instructores no acudiesen. En la habilitación, cada querella era leída oralmente y posteriormente, el asesor daba su parecer sobre si se tenía que publicar o no, aunque su opinión era meramente consultiva. Hecho esto, los visitadores votaban sobre la publicación o no de las querellas mediante escrutinio: antes, se había dispuesto en el centro de la sala una caja negra en la cual los visitadores podían introducir un boton blanco o un botón negro: en el caso que la mayoría de los botones fuesen negros, se seguía el parecer expresado por el asesor; en el caso que la mayoría de los botones fuesen blancos, se hacía lo contrario a lo expresado por el asesor ${ }^{46}$.

\footnotetext{
${ }^{43}$ Un ejemplo de reunión entre los asesores de la Visita y los doctores de la Real Audiencia: ACA, Generalidad, Serie G, 6/7/2, f. 38.

${ }^{44}$ Directori de la Visita..., 1636, pp. 11-13. Un ejemplo de delegación a un tercero de la capacidad de interrogar a un testigo en ACA, Generalidad, Serie G, 6/1/1, f. 57.

${ }^{45}$ Uno de los casos más detallados en los que un testigo se negó a declarar sucedió durante la Visita iniciada en septiembre de 1656. Los visitadores citaron a Josep Muxiga, doncel de Tortosa que, si bién en un principio acudió a declarar ante el consistorio, se negó a responder algunas de las preguntas de los Visitadores. Ante la actitud de Muxiga, los visitadores decidieron pedir consejo a los asesores, los cuales fueron partidarios que, en caso de nueva declaración e igual comportamiento del tortosino, se le encerrase en las cárceles de la Diputación, cosa que sucedió. Esta actuación por parte de los visitadores supuso una grave crisis entre la Visita y el Braç Militar, puesto que este último alegaba que Muxiga no podía ser hecho prisionero por motivos pecuniarios, por su condición de militar. Para seguir este caso: ACA, Generalidad, Serie G, 6/9, f. 96r-97r i ss.

${ }^{46}$ Directori de la Visita..., 1636, p. 13.
} 
Hecha la habilitación, los últimos días de la fase de la ofensa se dedicaban, normalmente, a la publicación de las querellas, que se hacía en una o más veces, atendiendo al volumen total de las mismas. Para la publicación, los visitadores realizaban una ceremonia en la cual se leían públicamente las querellas, ceremonia que contaba con la presencia de testigos y que normalmente se celebraba en la Sala dels Reis de la Casa de la Diputación, que había estado previamente preparada para la ocasión por parte de los miembros de la Diputación ${ }^{47}$. Después de la publicación de todas las querellas - las últimas se solían publicar el último dia de la ofensa, esto es, el 15 de diciembre- los visitadores hacían las últimas gestiones antes de entrar en la siguiente fase de la Visita, conocida como fase de la defensa.

\section{La instrucción pública: la fase de la «defensa»}

Una vez finalizado el plazo de los tres meses de la ofensa simbolizado con la publicación de las querellas de la Visita, las primeras gestiones de los visitadores tenían como objetivo adecentar el consistorio para la fase de la defensa. Durante los primeros tres meses, la sede de la Visita había estado cerrada "herméticamente" para evitar que las personas ajenas a la institución pudieran tener conocimiento de los procesos que en ella se estaban instruyendo. Iniciado ya el periodo de la defensa, todas las cerraduras y medidas de control se deshacían para que las personas que estuvieran acusadas en las querellas, pudiesen acceder a la escribanía de la Visita para pedir una copia escrita del proceso o bien la comunicación oral del mismo para poder preparar su defensa ${ }^{48}$.

Durante esta fase, los visitadores dejaban en cierto modo de ser los protagonistas: ahora eran los acusados los que tenían que demostrar su inocencia, llevando testigos favorables a su causa en el consistorio para que fuesen interrogados ${ }^{49}$. De hecho, para esta fase, cuantitativamente encontramos mucha menos documentación en los dietarios de la Visita que para la fase de la ofensa; y en los directorios apenas se hace referencia a este periodo. Además, en algunos casos esta documentación tiende a centrarse en aspectos de la institución más externos que internos ${ }^{50}$.

A nivel de organización interna, sabemos que durante la fase de la defensa, los visitadores realizaban diferentes cometidos. A la ya citada recepción de testigos propuestos por los acusados en las querellas, se le tienen que sumar tanto las gestiones

\footnotetext{
${ }^{47}$ Un buen ejemplo de la ceremonia en ACA, Generalidad, Serie G, 6/15, f. 79r-83r.

${ }^{48}$ Directori de la Visita..., 1636, p. 14. Sobre la comunicación de las querellas, en la visitas de 1647 y 1654 hubo cierta polémica sobre el precio a pagar por la copia escrita de las mismas. ACA, Generalidad, Serie G, 6/7, f. 66r-67r y ACA, Generalidad, Serie G, 6/8, f. 187 i ss.

${ }^{49}$ Aunque normalmente eran interrogados por los propios visitadores, algunas veces podían ser otros oficiales de la Visita los que escuchasen las declaraciones, como por ejemplo hizo el escribano mayor de la Visita en Febrero de 1623. ACA, Generalidad, Serie G, 6/1/1, f. 64v.

${ }^{50}$ Por ejemplo se recogen la asistencia de los consistoriales en las fiestas típicas como los Torneos o la recepción de personalidades.
} 
en materia de suspensiones de oficios hechas durante el periodo de la ofensa - retirar la suspensión en aquellos casos en que los oficiales dejasen de estar acusados-, como la recepción de documentación procedente de la inspección foránea ${ }^{51}$.

Otro de los aspectos recurrentes durante esta fase de la Visita, es la aparición de presiones hechas por otras instituciones públicas para que algunas de las querellas de la Visita no prosperasen. Por ejemplo, durante la Visita iniciada en 1635, el Consell de Cent, órgano rector de la vida municipal de la ciudad condal, mandó una embajada a los visitadores pidiéndoles que no se procediese en la querella presentada contra Francesc Joan Magarola, el cual había sido elegido Conseller en Cap -el cargo municipal más importante-. Los consellers, pretendían que los visitadores dejaran el enjuiciamiento para la próxima visita, aún cuando Magarola estaba acusado en dieciocho querellas, como les recordaban los visitadores en una embajada hecha a principios de marzo de 1636. La respuesta de los visitadores fue, en este caso, negativa $^{52}$. También la monarquía presionó a los visitadores para que no continuaran algunos procesos. Por ejemplo, en 1657, los visitadores habrían tenido que renunciar a continuar el proceso emprendido contra los diputados del trienio de 1654 por haber cobrado ilegalmente unas "alimaries" - un pago extra que recibían los oficiales coincidiendo con actos relevantes del calendario, por ejemplo la festividad de Sant Jordien motivo de una celebración que nunca se realizó ${ }^{53}$.

Aunque el episodio que más polvareda consiguió levantar, seguramente fue el que enfrentó a Don Juan José de Austria y al Consell de Cent con los visitadores del trienio de 1654-1656. La Visita del General, a diferencia de las otras instituciones separadas de la jurisdicción real en el Principado, después de 1652 no se vió afectada inmediatamente por las modificaciones impuestas por Felipe IV, reformas que tenían como objetivo un mayor control de la vida política catalana después del conflicto de la Guerra dels Segadors ${ }^{54}$. De hecho, los visitadores continuaron ejerciendo sus cargos con más o menos la misma intensidad que en los decenios anteriores y buena prueba de ello es que no dudaron en hacer una querella contra parte de los miembros de la Diputación del trienio de 1650-1654 — concretamente contra el diputado y presidente Pau del Rosso y el oidor de cuentas del brazo real Vicens Ferriol一. El principal delito

\footnotetext{
${ }^{51}$ ACA, Generalidad, Serie G, 6/3, f. 58v. En cuanto a la recepción de documentos procedentes de la inspección foránea, ACA, Generalidad, Serie G, 6/6/1, f. 88v-89r.

${ }^{52}$ Para seguir el enfrentamiento entre instituciones, ACA, Generalidad, Serie G, 6/4, f. 129v-130r, 142r$144 \mathrm{r}, 147 \mathrm{v}-148 \mathrm{v}, 156 \mathrm{v}-159 \mathrm{v}$.

${ }^{53}$ ACA, Generalidad, Serie G, 6/9, f. 141r-145v.

${ }^{54}$ Acerca de la nueva situación de las instituciones políticas catalanas después de 1652, vid. Eva Serra, "Catalunya després del 1652: recompenses, censura i repressió", Pedralbes. Revista d'Història Moderna, 17, 1997, pp. 191-215. De la misma autora: "El pas de rosca en el camí de l'austriacisme", en Del patriotisme al catalanisme: societat i politica (segles XVI-XIX), Vic, Eumo, 2001, pp. 71-104. Ver también: Antoni Simon, "1652. Entre la clemència i el càstig: teoria i pràctica política d'una repressió", en Segon Congrés Recerques: Enfrontaments civils: postguerres i reconstruccions. Lleida, 10-12 Abril 2002, Vol. III, Pagès Editors, pp. 27-44.
} 
del que se les acusaba era el haber creado en los meses finales del sitio de Barcelona dos consistorios paralelos, uno con sede en Barcelona y el otro con sede en Manresa. Para los visitadores, este hecho suponía un claro delito contra las leyes del Principado $\mathrm{y}$, por esto, decidieron mediante la sentencia de la querella número 1 que los acusados debían restituir los gastos derivados de la creación de un consistorio paralelo en Barcelona cuando el original se había trasladado a Manresa debido a la epidemia de peste que sufría la ciudad condal ${ }^{55}$.

De hecho, los visitadores ya habían recibido antes de la sentencia presiones para que la querella no prosperase ${ }^{56}$, pero fue precisamente en el momento de la publicación de la misma cuando el revuelo fue mayor. Otra vez, fueron los consellers de Barcelona los que se dirigieron a los visitadores para pedir la invalidación de la querella: según los consellers, la querella número 1 quedaba invalidada porque el Perdón General concedido por Felipe IV eximía a los diputados del trienio de 1650-1654 de todas sus acciones. Además, los consellers no dudaron en escribir a Don Juan José de Austria, por aquel entonces Lugarteniente General del Principado, para pedirle la anulación de la sentencia hecha por los visitadores, petición que les fue concedida. Ante esta situación, los visitadores decidieron escribir a los miembros de la Diputación del General para denunciar las acciones del hijo de Felipe IV que suponían una clara contrafacción del Capítulo 1 del Redreç de 1599. Los diputados, aceptaron los escritos presentados por los visitadores y decidieron convocar a sus asesores jurídicos para consultarles su parecer acerca de las acciones que se tenían que tomar. Según estos últimos, la sentencia de la Visita se ajustava a derecho y, por lo tanto, nadie podía pedir explicaciones a los visitadores con motivo de la publicación de la misma ${ }^{57}$.

Llegados a este punto, los diputados intentaron hacer recapacitar a Don Juan José de Austria. Entre el 10 de enero y el 10 de abril de 1655, le enviaron al menos tres embajadas para que modificase su decisión sobre la publicación de la sentencia de la querella número 1. Aunque la respuesta del lugarteniente a la primera de las embajadas

\footnotetext{
${ }^{55}$ DGC, vol. VI, pp. 609 y 1375.

${ }^{56}$ ACA, Generalidad, Serie G, 6/8, f. 216. Aunque no se dice explícitamente, creemos que la correspondencia entre los visitadores y Juan José de Austria durante los últimos días de Noviembre de 1654 -que coincidirían con los días finales de la fase de la defensa- probablemente gravitó entorno la problemática de la querella número 1; a diferencia de otros dietarios, en este las cartas no se conservaron o "desaparecieron", tal y como sugiere una entrada en el dietario de la Visita de 1656 en la que se acusa a algunos de los oficiales de la Visita de 1654 de haver sacado ilegalmente documentación del dietario de 1654 . ACA, Generalidad, Serie G, 6/9, f. 21v-23v.

${ }^{57}$ DGC, vol. VI, pp. 1380-1381. Los asesores de la Diputación eran muy explícitos en su voto: "attès singularment que en lo capítol 1 del nou redrés de les Corts del any 1599, està statuït y ordenat que los visitadors del General tinguen poder de visitar y conèixer de tots los excessos y culpes que 's trobarà aver comesos los deputats y hoïdors de comptes y officials del General, en virtut del qual poder an pogut conèixer los molt il lustres visitadors dels excessos comesos per lo dit doctor Paulo del Rosso y Vicens Farriol en lo formar consistori dins la present ciutat y gastos fets per dita ocasió, y en conseqüència conèixer de la nul-litat y justificació de aver format consistori dins la present ciutat, attès que la cognició de dits punts recauen sobre matèria pertinent a la administració de la Generalitat".
} 
fue "que lo mandaría ver y que con mucho gusto haría lo que fuesse benefficio del General y mandaría bolver la respuesta" 58 , el hijo de Felipe IV no cambió de parecer tan rápido. Sorprendentemente, parece ser que al final, la presión de la Diputación surgió efecto y Don Juan José de Austria permitió que se publicara la sentencia -o quien sabe si la ignoró ${ }^{59}$ - , recogida en el dietario de la Generalitat del trienio de $1654-1656^{60}$.

Pero de entre todas las referencias documentales que nos remiten a la fase de la defensa, hay una que, a nuestro entender, es la que mejor la define: estamos hablando de las alegaciones jurídicas que presentaban los acusados en las querellas al finalizar dicho período y que nos muestran en gran medida en que había consistido esta fase, esto es, en defenderse de las acusaciones vertidas por el consistorio de la Visita. Algunas de estas alegaciones, eran impresas $\mathrm{y}$, afortunadamente, unas pocas han llegado hasta nuestros días, como la que hizo imprimir Josep Jalpí i de Julià, Prior de Meià, Abogado Fiscal del General entre 1662 y 1668, conservada en el fondo antiguo de la Biblioteca Universitària de Barcelona ${ }^{61}$.

La alegación jurídica presenta una estructura sencilla pero al mismo tiempo directa: la primera parte de la misma - páginas 1 a 3- se dedica a la exposición de los motivos por los cuales tanto el procurador fiscal de la Visita, como los testigos aportados por este, habrían llegado a la conclusión que el acusado sería culpable del delito. En este caso, concretamente, del delito de no haver impedido una ceremonia de insaculación errónea en la cual los miembros de la Diputación del trienio de 1662 1665 se habrían repartido "alimàries" por valor de más de 942 libras. La segunda parte de la alegación - páginas 4 a 10- se centra en contrarrestar todos los argumentos planteados por la acusación, extensamente y citando tanto la propia ley vigente -Derecho público catalán- como obras de jurisconsultos, tanto catalanes como no catalanes ${ }^{62}$. Finalmente, el interesado concluye la alegación con una petición de absolución respecto del contenido de la querella — página 10—.

\footnotetext{
${ }^{58}$ Ibid., pp. 609.

${ }^{59}$ Según el testimoniaje de los Dietaris de la Generalitat de Catalunya, no se puede asegurar ninguna de las dos opciones.

${ }^{60}$ La sentencia dice: "Les quals cosas y altres, atteses dels mèrits del procés resultants y atrament, sentenciam, pronunciam y declaram [...] que fonch nul·lo y contra capítols de Cort lo que dits deputats y oïdors entengueren tenir en la present ciutat [Barcelona] en lo mateix temps y, per consegüent, [...] declaram nul los tots los procehiments, deliberacions y actes per aquests plets en nom del consistori de deputats y oïdors de comptes del General de Cathalunya [...] havent de ésser condempnats, com de present condempnam a refer, esmenar y pagar al General lo valor de totes les pecúnies del General que per orde o deliberació de aquells són estades en dit temps gastades”. DGC, vol. VI, p. 1431.

${ }^{61}$ La alegación se conserva en BUB, Fons Antic, 07 C-239/1/13-13. La impresión de las alegaciones jurídicas para defenderse de las acusaciones vertidas por los visitadores, suponemos que no estaba al alcance de todos, puesto que el interesado había de pagar tanto el trabajo jurídico, hecho normalmente por uno o más doctores en derecho, como la posterior impresión. Seguramente, las personas que se lo podían permitir, mandaban imprimir varias copias de su alegación para repartirlas entre los miembros de la clase dirigente de la ciudad condal, con el objetivo de crear una opinión pública favorable a su causa.

${ }^{62}$ Cita, en la página 6, entre muchos otros, un fragmento de la Política para Corregidores de Jerónimo Castillo de Bobadilla.
} 
Días antes de finalizar el período de la defensa, los visitadores instructores de procesos escribían al resto de los consistoriales para que se presentasen a Barcelona antes del dia 15 de marzo, que normalmente coincidía con el último dia de la fase de la defensa $^{63}$. En algunos ejemplares de los dietarios de la Visita también encontramos la descripción de la última jornada antes de empezar los últimos tres meses dedicados a la elaboración de las sentencias: probablemente los visitadores ordenaban levantar acta de su presencia en el consistorio en los últimos momentos de la fase para que posteriormente, los sentenciados que no hubiesen aprovechado los tres meses de la defensa, no pudiesen alegar que no habían tenido oportunidad de presentar sus testimonios ante los visitadores ${ }^{64}$.

\section{Los últimos tres meses: la fase de las sentencias}

Finalizado el plazo de los tres meses dedicados a la defensa, los visitadores encaraban el período dedicado a la confección de las sentencias. Los distintos ordenamientos coinciden en señalar como indispensable la presencia de los nueve visitadores en esta fase de la Visita ${ }^{65}$. Ahora, los acusados podían recusar cualesquiera de los oficiales de la Visita que consideraran que pudieran tener intereses en la o las querellas que se estuvieran discutiendo ${ }^{66}$. Eran estos los meses que podían tener más trascendencia en un futuro, debido a que como recogía el capítulo 1 del Redreç de 1599, las sentencias no podían ser motivo de recurso ${ }^{67}$. Los visitadores, sabedores de la relevancia del momento, podían consultar sus dudas juntando a comités de expertos juristas en todos aquellos casos que fuese necesario ${ }^{68}$.

La carga de trabajo durante los últimos días antes de la publicación de las sentencias podía obligar a los visitadores a modificar los horarios para tratar de finalizar todas las sentencias a tiempo. Por ejemplo, en mayo de 1624, los visitadores decidieron a instancias del procurador fiscal, que hasta el dia de la ceremonia de la publicación de las sentencias, los visitadores y el resto de oficiales y oficios de la Visita hubieran de residir en el consistorio todos los días de la semana, incluyendo los festivos. El motivo era muy claro: se tenían que sentenciar más de 130 procesos y si-

\footnotetext{
${ }^{63}$ Un ejemplo de cartas enviadas a los visitadores no instructores para reclamar su presencia antes del inicio de la fase de las sentencias en ACA, Generalidad, Serie G, 6/7/1, f. 74 .

${ }^{64}$ ACA, Generalidad, Serie G, 6/8, f. 217r-218r.

${ }^{65}$ Directori de la Visita..., 1636, pp. 14-15. Directori de la Visita..., 1672, p. 17.

${ }^{66}$ Directori de la Visita..., 1636, p. 15. Un ejemplo de recusación en ACA, Generalidad, Serie G, 6/1/2, f. 39v. Concretamente, el oficial recusado era Josep Montaner, asesor de la Visita, que no podría participar en las querellas 32, 34, 79, 86, 88, 136 y 158. Lo sustituyó Joan Sabater, ayudante del asesor.

${ }^{67}$ Como vimos, este hecho cambia a partir de 1660, con la aceptación de los recursos por la Real Audiencia de Cataluña.

${ }^{68}$ Como sucedió, por ejemplo, con la querella número 14 en la Visita del año 1623. ACA, Generalidad, Serie G, 6/1/1, f. 70v-72r. También se dió semejante caso en la querella número 4, en la Visita del año 1638. ACA, Generalidad, Serie G, 6/5, f. 208v-209v y 230r-232r.
} 
guiendo con el mismo ritmo de trabajo empleado hasta la fecha, el objetivo se antojaba imposible ${ }^{69}$.

A medida que se acercaban los últimos días de la Visita, los visitadores se disponían a votar cuales sentencias serían finalmente publicadas y cuales no. Antes de hacer esta votación, según el Directorio de 1636, los visitadores volvían a leer todo el proceso, momento en el cual, cada acusado podía hacer un "alegato final" para hacer las consideraciones que creyera oportunas ${ }^{70}$. Realizado este paso, el asesor daba su parecer acerca de la sentencia, es decir, si pensaba que debía publicarse o no. Acto seguido, los visitadores ejercían su voto. En caso de encontrarse más botones negros que blancos en la urna, se seguía la opinión del asesor. Si no se daba este caso -es decir, si se encontraban más botones blancos que negros dentro de la urna- se volvía a votar, esta vez siendo el presidente de la Visita -uno de los visitadores, normalmente el eclesiástico con más rango- el que proponía su parecer. En caso de suceder como con el asesor, es decir, que los botones blancos superaran a los negros y, por consiguiente, que la mayoría de los visitadores no estuviera de acuerdo con la proposición, se volvía a repetir la votación, aunque antes se discutía internamente los elementos de la sentencia a cambiar para conseguir el acuerdo de la mayoría. En el caso de no llegar a un acuerdo, el consistorio podía no tomar resolución sobre la querella en cuestión ${ }^{71}$.

Votadas las sentencias, aquellas que hubieran sido aprobadas para su publicación, eran trasladadas al asesor, que se encargaba de darles la forma conveniente para su posterior publicación. Hechas estas modificaciones, se volvían a leer y los visitadores elegían fecha para la primera ceremonia de publicación de las sentencias ${ }^{72}$. Dicha ceremonia, se celebraba en una de las estancias de la Casa de la Diputación, en Barcelona, conocida como Sala dels Reis. Los nueve visitadores, acompañados del resto de oficiales de la institución, salían de su consistorio y en escrupuloso órden, se dirigían a la ya citada Sala dels Reis, que se había preparado para la ocasión. Una vez allí, los visitadores se sentaban en unos bancos justo detrás del bufete o mesa que separaba los consistoriales de los testigos que asistían a la publicación. Estando sentados, el escribano mayor de la Visita tomaba la palabra para hacer la lectura de las sentencias. Finalizada la lectura de todas las sentencias, el escribano mayor tomaba nota de los principales testigos presentes y, posteriormente, los visitadores y los oficiales de la Visita volvían a su consistorio bajo el mismo órden seguido durante el viaje de ida ${ }^{73}$.

\footnotetext{
${ }^{69}$ ACA, Generalidad, Serie G, 6/1/1, f. 78r.

${ }^{70}$ Directori de la Visita..., 1636, p. 15.

${ }^{71}$ Ibid., p. 15-16.

${ }^{72}$ Ibid., p. 16.

${ }^{73}$ Ibid., p. 16-17. También podemos encontrar la descripción de la ceremonia de la publicación de las sentencias en varios dietarios de la Visita. Un ejemplo en ACA, Generalidad, Serie G, 6/4, f. 182r-183v. En este caso, los testigos presentes fueron varios, aunque se recoge el nombre de los cuatro más relevantes: el canónigo Josep Rovira i Boldo, el noble Pedro de Reguer, Pere Montserrat i Rufet, doctor en derecho, y Jeroni de Navel, ciudadano honrado.
} 
Después de la ceremonia de publicación —normalmente pasados tres días-, el procurador fiscal de la Visita pedía el decreto de ejecución de las sentencias. Hecha esta petición, los visitadores redactaban los decretos. El directorio hace hincapié en la necesidad que los visitadores no introdujesen cambios en las sentencias a petición de los condenados - lo que nos hace sospechar que era una práctica más o menos recurrente-, aunque en el caso de haberse producido algún error durante la redacción de la sentencia, este se podía subsanar en el decreto de ejecución de la misma ${ }^{74}$.

Los decretos de ejecución hechos por los visitadores tenían que ser ejecutados, ya fuera por los propios visitadores, ya fuera por los diputados en el caso que los nueve meses de la Visita ya hubieran finalizado. A pesar de esta premisa, sabemos que a menudo se produjeron dificultades en la aplicación de los decretos hechos por los visitadores. Por ejemplo los visitadores de la Visita iniciada en 1626, se quejaban amargamente en mayo de 1627 a los diputados porque estos no ejecutaban una de las sentencias ${ }^{75}$. A pesar de ello, en muchas ocasiones, los visitadores no esperaban a ver si las sentencias eran o no ejecutadas. En la mayoría de trienios, una vez finalizado el plazo previsto por las Cortes de nueve meses para la Visita, los consistoriales finalizaban su actividad, entregando toda la documentación inherente a la institución a la Diputación para que esta la guardase en sus archivos. Junto a la documentación, los visitadores también solían entregar los memoriales con las sentencias, las penas pecuniarias que los sentenciados tenían que pagar y los decretos de ejecución aún pendientes ${ }^{76}$.

\section{Conclusiones}

Llegados a este punto, creemos que la pregunta más interesante que nos podemos plantear es si la Visita del General como mecanismo de fiscalización de la actividad de los oficiales públicos cumplió o no su cometido. Según se puede observar en la documentación creemos que hay argumentos tanto en un sentido como en el otro.

Por un lado, a nuestro parecer, las ejecuciones de las sentencias fueron el verdadero talón de aquiles de la institución, tal y como lo reconocían los mismos visitadores en un memorial con destino a la Corte, en Diciembre de $1674^{77}$. Según los visitadores, la falta de ejecuciones de las sentencias había desencadenado una situación ciertamente absurda, por la cual todos los condenados eran inscritos en el "Llibre de Vàlues del General" -libro donde se inscribían los deudores recientes de la administración de la Diputación-, aunque los diputados nunca ejercían el cobro de las deudas. El resultado: los particulares condenados en las visitas adeudaban a la hacienda del Ge-

\footnotetext{
${ }^{74}$ Directori de la Visita..., p. 18.

${ }^{75}$ ACA, Generalidad, Serie G, 6/1/2, f. 43r-46r.

${ }^{76}$ ACA, Generalidad, Serie G, 6/18, f. 145v-146r.

${ }^{77}$ El memorial lo encontramos dentro el dietario de la Visita de 1674. ACA, Generalidad, Serie G, 6/15, f. $78-2$ a y $78-3 a$.
} 
neral un total de más de 774.366 libras, y esto sin contar las deudas antiguas, recogidas en otro de los libros de contabilidad de la Diputación, conocido como "Fernando Paga". Además, aunque los condenados que eran anotados como deudores no podían en ningún caso conseguir cargos en la Diputación hasta que pagaran lo adeudado, a partir de 1660, con el reconocimiento de la posibilidad de recorrer las sentencias ante la Real Audiencia, alegaban que mientras no se dictara sentencia se les dejase ejercer los cargos. Esto hacía que nadie pagase ya sus deudas para evitar salir del sistema político. Para los visitadores la conclusión era evidente: "La Visita es de poco o de ningún beneficio por todas estas causas".

Otro aspecto a tener en cuenta, sería el elevado coste de algunas de las Visitas, siendo la más cara de todas la de 1621, con un coste aproximado de unas 24.000 libras, hecho que propició que los contemporáneos pusieran el grito en el cielo ${ }^{78}$.

A pesar de todo y por el contrario, hay diversos argumentos positivos a destacar sobre el papel de la institución.

1. En primer lugar, la creación de recopilaciones de ordenamientos sobre los oficios de la Generalitat, como el conocido como Llibre de la Visita de $1621^{79}$, El libro de Capítulos sobre la gestión de la esquadra de galiotes de la Diputación ${ }^{80}$, o el Sumari dels Cullidors de 1657 o de las obligaciones de los oficiales encargados de la recaptación de las tasas impuestas por la Generalitat ${ }^{81}$. Solamente el hecho de que sucesivas Visitas fueran capaces de seleccionar y hacer encuadernar estas auténticas recopilaciones ya nos puede indicar que, al menos en cierto modo, la Visita funcionó, puesto que los visitadores se dieron cuenta que muchas de las veces, los fraudes cometidos por los oficiales de la Generalitat se escudaban en el desconocimiento de la legislación vigente ${ }^{82}$.

2. En segundo lugar, la constatación que de aplicarse las ejecuciones de las sentencias hechas por los visitadores, la Generalitat podía verse ampliamente beneficiada,

\footnotetext{
${ }^{78}$ ACA, Generalidad, Serie G, 6/6/1, f. 6r-7v. Sobre la Visita de 1621, vid. Josep Capdeferro, El vigor de les institucions..., pp. 60-69.

${ }^{79}$ Capitols resultants de las sententias fetas per los molt illustres senyors visitadors del General de Cathalunya acerca dels carrechs dels officials de la Casa de la Deputacio y General de Barcelona y altres publicades en lo any MDCXXI, Barcelona, Geroni Margarit, 1621. Ejemplar disponible en Biblioteca de Catalunya, 11-II-35.

${ }^{80}$ Capitols y desliberations resultants de las sententias fetas per los Molt Illustres Senyors Visitadors del General de Cathalunya acerca dels carrechs dels officials de la Squadra de las Galeras de Cathalunya y altras subjectes a la present visita : publicadas en lo any MDCXXI, Barcelona, Geroni Margarit, 1621. Ejemplar disponible en Biblioteca de Catalunya, 11-II-35.

${ }^{81}$ Summari dels carrechs y obligations dels Collidors, Taulers ò Receptors, dels drets de la Generalitat del present Principat de Cathalunya y Comptats de Rossello y Cerdanya, per Capitol de Corts, ordinations del Generals y per sentèntias de visitas inposadas, Barcelona, 1657. Ejemplar disponible en BUB, Fons Antic, 07 B-58/4/24.

${ }^{82}$ Por ejemplo, en la deliberación hecha el dia 18 de Mayo de 1657 en la que los visitadores decidieron mandar imprimir el Sumari dels Collidors de 1657, se justificaba la impresión del mismo para evitar, precisamente, este supuesto. ACA, Generalidad, Serie G, 6/9, f. 177v-179v. Cfr. Josep Capdeferro, El vigor de les institucions..., p. 66.
} 
puesto que además de corregir comportamientos fraudulentos de sus oficiales, podía subsanar muchos de sus problemas hacendísticos. El mejor ejemplo de esto lo podemos encontrar en el Sumario de la Visita de 1626. En la sexta y la séptima rúbricas, se recogen las cantidades que la Diputación pasaría a ingresar después de la correcta aplicación de las sentencias de la Visita: el montante final asciende a más de 97.000 libras $^{83}$, una cantidad muy importante y claramente superior a las 24.000 libras gastadas en la ya citada Visita de 1621, que fue en la que más se gastó ${ }^{84}$.

3. En tercer lugar, y por último, creemos que la propia percepción de los coetáneos respecto de la institución nos puede dar a entender que su papel, aunque con claroscuros, fue positivo. Nuestra afirmación se basa en el hecho que en las Cortes Catalanas de 1701-1702, celebradas más de cien años después de la úlitma reunión finalizada con éxito -la de 1626-32 no llegó a culminarse nunca-, los estamentos volvieron a ponerse de acuerdo para reformar la Visita del General e, incluso, para reafirmar su autoridad ${ }^{85}$. Realmente, si los miembros de las Cortes hubieran creído que la fiscalización de los oficiales públicos no servía de mucho, probablemente no hubieran hecho el esfuerzo de volver a actualizar la Visita.

\footnotetext{
${ }^{83}$ Sumari, compendios..., 1628, f. 32r-35v.

${ }^{84}$ Por ejemplo, por una noticia recogida en el dietario de la Visita de 1641, sabemos que en 1605 se gastaron poco más de 9.600 libras en la Visita. También en esta noticia viene recogido el gasto de la Visita de 1621. ACA, Generalidad, Serie G, 6/6/1, f. 6r-7v.

${ }^{85}$ El nuevo "Redreç" reformaba de nuevo la Visita, introduciendo, como principal novedad, un sistema de apelación propio para evitar que las sentencias de la Visita se pudieran recurrir en la Real Audiencia. ACA, Generalitat, Serie G, 233/2, capítulo 32. Además, en las mismas cortes, se hizo redactar un Capítulo de Corte específico -19/1702- en el que se prohibía expresamente la posibilidad de recurrir las sentencias de la Visita. Constitucions, capitols $i$ actes de Cort, 1701-1702 i 1705-1706, Generalitat de Catalunya, Barcelona, 2006. p. 16. Tenemos que agradecer esta última referencia al profesor Josep Capdeferro i Pla.
} 